\title{
PENGARUH KECEMASAN IBU TERHADAP PROSES PERSALINAN KALA 1 FASE AKTIF DI BPS ATIK SUHARIJATI SURABAYA
}

\author{
Nur Masruroh* \\ Fakultas Keperawatan dan Kebidanan \\ Universitas Nahdlatul Ulama Surabaya J1. Smea 57 Surabaya \\ Email : nurmasruroh@yahoo.com
}

\begin{abstract}
Abstrack: The relationship with the mother's level of anxiety in the first stage of labor active phase in BPM Atik Suharijati Surabaya. Mothers who experienced the process of labor is a physiological thing, but in reality people still think childbirth is a life and death stakes. Mothers who give birth experience anxiety levels cause birth becomes pathological. This study aims to determine the relationship with the mother's level of anxiety in the first stage of labor active phase in BPM Atik Suharijati Surabaya. Design analytical research with cross sectional approach. The population around the third trimester pregnant women who face labor in BPS Atik Suharijati in April-May 2015 of 25 respondents. A sample of 12 respondents in October was taken with the technique of "purposive sampling". Independent variables and the dependent variable levels of anxiety long active phase. Collecting data using questionnaires and partograf. Data were analyzed using the Mann Whitney test with a significance level $\alpha=0.05$. The results showed nearly half $(41.7 \%)$ had mild anxiety and the majority of respondents $(75 \%)$ had active phase $<6$ hours. Statistical test results obtained $\rho=0.024<\alpha=0.05$, H0 is rejected means that there is a relationship with the mother's level of anxiety in the first stage of labor active phase in BPS Atik Suharijati. The conclusions of this study is the higher the mother's level of anxiety, the more disturbing the birth process to be gone through. So that health workers are expected to continue to provide information or understanding to pregnant women about childbirth and the factors that influence it.
\end{abstract}

Abstrak: Pengaruh kecemasan ibu terhadap terhadap proses persalinan kala 1 Fase aktif di BPS Atik Suharijati Surabaya. Ibu yang mengalami proses persalinan adalah hal yang fisiologis, namun pada kenyataannya masyarakat masih menganggap persalinan merupakan pertaruhan hidup dan mati. Ibu yang akan melahirkan mengalami tingkat kecemasan menyebabkan persalinan menjadi patologis. Penelitian ini bertujuan untuk mengetahui pengaruh tingkat kecemasan ibu dengan proses persalinan pada kala I fase aktif di BPM Atik Suharijati Surabaya. Desain penelitian analitik dengan pendekatan cross sectional. Populasinya seluruh ibu hamil trimester III yang akan menghadapi persalinan di BPM Atik Suharijati pada bulan Juli, Juli sebanyak 25 responden. Sampel sebesar 12 responden pada bulan Juli diambil dengan teknik "Purposive sampling". Variabel independent tingkat kecemasan dan variabel dependen lama fase aktif. Pengumpulan data menggunakan kuesioner dan partograf. Data dianalisa menggunakan uji Mann Whitney dengan tingkat kemaknaan $\alpha=0,05$. Hasil penelitian menunjukkan hampir setengahnya $(41.7 \%)$ mengalami cemas ringan dan sebagian besar responden $(75 \%)$ mengalami fase aktif $<6$ jam. Hasil uji statistik didapatkan $\rho=0,024<\alpha=0,05$, maka $\mathrm{H}_{0}$ ditolak artinya ada pengaruh tingkat kecemasan ibu dengan proses persalinan pada kala I fase aktif di 
BPM Atik Suharijati Surabaya. Simpulan dari penelitian ini adalah semakin tinggi tingkat kecemasan ibu maka semakin mengganggu proses persalinan yang akan dilaluinya. Sehingga bagi tenaga kesehatan diharapkan dapat terus memberikan informasi atau pemahaman kepada ibu hamil tentang proses persalinan dan faktor yang mempengaruhinya.

Kata Kunci: Kecemasan, Fase aktif, persalinan

\section{PENDAHULUAN}

Setiap wanita yang hamil dihadapkan pada beberapa keadaan yang mungkin dapat terjadi sehubungan dengan kehamilannya itu, seperti perkembangan dan keselamatan janin dalam kandungannya sampai tiba waktunya untuk dilahirkan. Persalinan merupakan kejadian fisiologis yang normal dilalui oleh ibu dan proses persalinan menuntut pengorbanan seorang ibu. Masyarakat masih menganggap persalinan merupakan pertaruhan hidup dan mati, sehingga ibu yang akan melahirkan mengalami kecemasan (Erawati, 2010).

Faktor-faktor yang mempengaruhi proses persalinan yaitu, faktor ibu (power, passage, psicology), faktor janin (plasenta) dan faktor penolong persalinan. Hal ini sangat penting, mengingat beberapa kasus kematian ibu dan bayi di sebabkan oleh tidak terdeteksinya secara dini adanya salah satu dari faktor faktor tersebut.

Kehamilan merupakan episode dramatis terhadap kondisi biologis, perubahan psikologis dan adaptasi dari seorang wanita yang pernah mengalaminya sejak saat hamil, ibu sudah mengalami kecemasan. kecemasan meningkat menjelang persalinan terutama pada trimester tiga. Bagi seorang ibu hamil ketika menjelang persalinan cenderung mengalami rasa cemas jika rasa cemas ini berlebihan maka dapat mengakibatkan partus lama dan. Kecemasan ibu menjelang proses persalinan dipengaruhi oleh beberapa faktor di antaranya: kehamilan pada usia usia kurang dari 20 tahun dan lebih dari 35 tahun akan memberi dampak terhadap perasaan takut dan cemas menjelang persalinan, karena usia ini merupakan usia kategori kehamilan beresiko tinggi dan seorang ibu yang berusia lebih lanjut akan menanggung resiko yang semakin tinggi untuk melahirkan bayi cacat lahir (Susiati, 2008).

Solusi atau dukungan yang diberikan pada ibu terutama dukungan yang di peroleh dari suami atau keluarga akan menimbulkan perasaan tenang, senang , sikap positif, sedangkan solusi dari tim medis (Bidan atau Dokter kandungan) harus benar-benar memperhatikan yang akan dialami Ibu saat persalinan baik secara fisik maupun psikososial.

\section{METODE PENELITIAN}

Desain yang digunakan dalam penelitian ini adalah analitik dengan tujuan untuk mengetahui pengaruh tingkat kecemasan ibu hamil trimester III dalam menghadapi persalinan normal. Dengan rancang bangun yang digunakan adalah Cross Sectional yaitu jenis penelitian yang menekankan pada waktu pengukuran atau observasi data hanya satu kali pada satu saat. 
Pada penelitian ini sampel diambil seluruh ibu hamil trimester III yang menghadapi persalinan pada bulan AprilMei di BPS Atik Suharijati berjumlah 12 orang.

Dalam penelitian ini dilakukan pengambilan sampel dengan teknik purposive Sampling Dalam penelitian ini tidak semua responden yang akan melahirkan akan dilakukan penelitian oleh peneliti. Hanya responden yang mengalami fase aktif pada pembukaan 4,5,6,7 atau sesuai dengan keadaan responden (mampu berkomunikasi dengan peneliti dan mampu mengisi lembar kuesioner).

\section{HASIL PENELITIAN}

a. Data Umum

Data responden yang telah dikumpulkan kemudian diolah dan dikelompokkan pada beberapa karakteristik, hasil yang didapat sebagai berikut:

1) Karakteristik Responden Berdasarkan Usia.

Karakteristik usia menurut Depkes RI (2009) dibagi menjadi beberapa bagian antara lain: remaja akhir (17-25 tahun). Dewasa awal (26-35 tahun), dan dewasa akhir (35-45 tahun).

Tabel 5.1 Distribusi frekuensi responden berdasarkan umur ibu bersalin di BPM Atik Suharijati Surabaya bulan Mei 2015

\begin{tabular}{llll}
\hline No & $\begin{array}{l}\text { Umur } \\
\text { (tahun) }\end{array}$ & Jumlah & $\begin{array}{l}\text { Persentase } \\
(\%)\end{array}$ \\
\hline 1 & $17-25$ & 6 & 50 \\
2 & $26-35$ & 3 & 25 \\
3 & $36-45$ & 3 & 25 \\
\hline & Total & 12 & 100 \\
\hline
\end{tabular}

Sumber: Data Primer, April-Mei 2015
Hasil penelitian pada tabel 5.1 menunjukkan bahwa dari 12 responden, setengahnya (50\%) berumur 17-25 tahun.

2) Karakteristik Responden Berdasarkan Pendidikan.

Menurut Undang-undang sistem Pendidikan Nasional Nomor 20 tahun 2003, pendidikan dibagi menjadi 3 yaitu pendidikan dasar (SD, SMP), pendidikan menengah (SMA), dan pendidikan tinggi. (hukumonline.com)

Tabel 5.2 Distribusi frekuensi responden berdasarkan pendidikan ibu bersalin di BPM Atik Suharijati Surabaya bulan Mei 2015

\begin{tabular}{llll}
\hline No & Pendidikan & Jumlah & $\begin{array}{l}\text { Persentase } \\
(\%)\end{array}$ \\
\hline 1 & Dasar & 0 & 0 \\
2 & Menengah & 9 & 75 \\
3 & Tinggi & 3 & 25 \\
\hline & Total & 12 & 100 \\
\hline
\end{tabular}

Sumber: Data Primer, April-Mei 2015

Hasil penelitian pada tabel 5.2 menunjukkan bahwa dari 12 responden, sebagian besar $(75 \%)$ berpendidikan menengah.

3) Karakteristik Responden Berdasarkan Tingkat Ekonomi.

Dibagi menjadi ekonomi kurang (penghasilan < 1.000.000), ekonomi cukup (penghasilan 1.000.000 2.000.000) dan ekonomi baik ( > 2.000.000) dapat dilihat dari tabel 5.3 dibawah ini:

Tabel 5.3 Distribusi Frekuensi responden berdasarkan ekonomi ibu di 


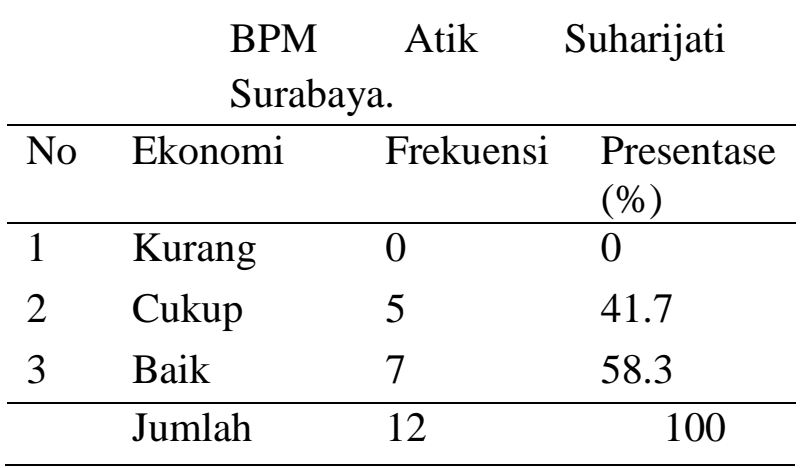

Sumber : Data Primer, April-Mei 2015

Berdasarkan tabel 5.3 menunjukkan bahwa dari 12 responden sebagian besar (58.3\%) memiliki ekonomi yang baik.

4) Karakteristik Responden Berdasarkan Perolehan Informasi.

Informasi merupakan fungsi penting untuk membantu mengurangi rasa cemas. Semakin sering seseorang memperoleh informasi, semakin meningkat pula pengetahuan yang dimiliki seseorang yang dapat mempengaruhi tingkat kecemasan.

Tabel 5.4 Distribusi frekuensi responden berdasarkan perolehan sumber informasi tentang persalinan di BPM Atik Suharijati di Surabaya bulan Mei 2015

\begin{tabular}{llll}
\hline No & $\begin{array}{l}\text { Perolehan } \\
\text { Sumber } \\
\text { Informasi }\end{array}$ & Jumlah & $\begin{array}{l}\text { Persentase } \\
(\%)\end{array}$ \\
\hline 1 & $\begin{array}{l}\text { Tidak } \\
\text { pernah }\end{array}$ & 0 & 0 \\
2 & Pernah & 12 & 100 \\
\hline & Total & 12 & 100 \\
\hline
\end{tabular}

Sumber: Data Primer, April-Mei 2015

Hasil penelitian pada tabel 5.4 menunjukkan seluruhnya (100\%) pernah memperoleh informasi.

5) Karakteristik responden berdasarkan sumber informasi
Sumber informasi dapat diperoleh dari beberapa cara antara lain: penyuluhan mahasiswa, dari petugas kesehatan, media massa, dari saudara atau kerabat.

Tabel 5.5 Distribusi frekuensi responden berdasarkan sumber informasi yang diperoleh ibu hamil trimester I di BPM Atik Suharijati Surabaya bulan Mei 2015

\begin{tabular}{|c|c|c|c|}
\hline No & $\begin{array}{l}\text { Sumber } \\
\text { Informasi }\end{array}$ & Jumlah & $\begin{array}{l}\text { Persentase } \\
(\%)\end{array}$ \\
\hline 1 & $\begin{array}{l}\text { Penyuluhan } \\
\text { Mahasiswa }\end{array}$ & 3 & 25 \\
\hline 2 & $\begin{array}{l}\text { Petugas } \\
\text { Kesehatan }\end{array}$ & 7 & 58,5 \\
\hline 3 & $\begin{array}{l}\text { Media } \\
\text { Massa }\end{array}$ & 0 & 0 \\
\hline 4 & $\begin{array}{l}\text { Saudara/ } \\
\text { Kerabat }\end{array}$ & 2 & 16,7 \\
\hline & Total & 12 & 100 \\
\hline
\end{tabular}

Sumber: Data Primer, April-Mei 2015

Hasil penelitian pada tabel 5.5 menunjukkan dari 12 responden sebagian besar $(58,3 \%)$ memperoleh informasi dari tenaga kesehatan.

6) Karakteristik Responden Berdasarkan Paritas.

Karakteristik paritas menurut Mochtar (1998) antara lain: Nulipara yaitu seseorang yang belum pernah melahirkan bayi viable,primipara yaitu seseorang yang pernah melahirkan bayi viable untuk pertama kali, multipara yaitu seseorang yang pernah melahirkan bayi viable beberapa kali (sampai 4 kali), dan grande multipara yaitu seseorang yang pernah melahirkan bayi viable lebih dari 4 kali.

Tabel 5.6 Distribusi frekuensi responden berdasarkan paritas Ibu Bersalin di BPM Atik Suharijati di Surabaya bulan April-Mei 2015 


\begin{tabular}{llll}
\hline $\begin{array}{l}\mathrm{N} \\
\mathrm{o}\end{array}$ & Paritas & $\begin{array}{l}\text { Jumla } \\
\mathrm{h}\end{array}$ & $\begin{array}{l}\text { Persentas } \\
\mathrm{e}(\%)\end{array}$ \\
\hline 1 & Nulipara & 4 & 33.3 \\
2 & Primipara & 5 & 41.7 \\
3 & Multipara & 3 & 25 \\
4 & Grandemultipa & 0 & 0 \\
& ra & & \\
\hline & Total & 12 & 100 \\
\hline
\end{tabular}

Sumber : Data Primer, April-Mei 2015

Hasil penelitian pada tabel 5.6 menunjukkan bahwa dari 12 responden hampir setengahnya $(41.7 \%)$ adalah primipara.

7) Karakteristik Responden Berdasarkan Pendamping Saat Persalinan.

Dukungan keluarga sangat mempengaruhi tingkat kecemasan seseorang, pendampingan pada saat persalinan diharapkan mampu membantu mengurangi tingkat kecemasan pada saat persalinan

Tabel 5.7 Distribusi frekuensi responden berdasarkan pendamping saat persalinan di BPM Atik Suharijati di Surabaya bulan April-Mei 2015

\begin{tabular}{llll}
\hline $\mathrm{N}$ & Paritas & $\begin{array}{l}\text { Jumla } \\
\mathrm{h}\end{array}$ & $\begin{array}{l}\text { Persentas } \\
\mathrm{e}(\%)\end{array}$ \\
\hline 1 & $\begin{array}{l}\text { Tidak ada } \\
\text { pendamping }\end{array}$ & 6 & 50 \\
2 & $\begin{array}{l}\text { Suami/anggot } \\
\text { a keluarga }\end{array}$ & 6 & 50 \\
\hline & Total & 12 & 100 \\
\hline
\end{tabular}

Sumber : Data Primer, April-Mei 2015

Hasil penelitian pada tabel 5.7 menunjukkan bahwa dari 12 responden setengahnya (50\%) tidak ada pendampingan saat proses persalinan. b. Data Khusus

Data ini terdiri dari tingkat pengetahuan ibu hamil tentang tingkat kecemasan dengan proses persalinan kala 1 fase aktif trimester I di BPM Atik Suharijati Surabaya pada tanggal 6 AprilMei - 26 April-Mei 2015 sebesar 12 responden. Dan hasil penelitian ini didapatkan :

1) Karakteristik Responden Berdasarkan Tingkat Kecemasan

Untuk mengetahui distribusi frekuensi tentang tingkat kecemasan ibu dapat dilihat dari table berikut:

Tabel 5.8 Distribusi frekuensi responden menurut tingkat kecemasan ibu di BPM Atik Suharijati di Surabaya bulan April-Mei 2015

\begin{tabular}{|c|c|c|c|}
\hline No & $\begin{array}{l}\text { Tingkat } \\
\text { Kecemasan }\end{array}$ & Jumlah & $\begin{array}{l}\text { Persentase } \\
(\%)\end{array}$ \\
\hline 1 & $\begin{array}{l}\text { Tidak } \\
\text { Cemas }\end{array}$ & 2 & 16.7 \\
\hline 2 & $\begin{array}{l}\text { Cemas } \\
\text { Ringan }\end{array}$ & 5 & 41.7 \\
\hline 3 & $\begin{array}{l}\text { Cemas } \\
\text { Sedang }\end{array}$ & 4 & 33.3 \\
\hline 4 & $\begin{array}{l}\text { Cemas } \\
\text { Berat }\end{array}$ & 1 & 8,3 \\
\hline 5 & $\begin{array}{l}\text { Cemas } \\
\text { Sangat } \\
\text { Berat }\end{array}$ & 0 & 0 \\
\hline & Total & 12 & 100 \\
\hline \multicolumn{4}{|c|}{$\begin{array}{l}\text { Sumber: Data Primer, April-Mei } 2015 \\
\text { Hasil penelitian pada tabel } 5.8 \\
\text { menunjukkan bahwa dari } 12 \text { responden } \\
\text { hampir setengahnya }(41.7 \%) \text { mengalami } \\
\text { tingkat kecemasan ringan. }\end{array}$} \\
\hline
\end{tabular}

2) Karakteristik Responden Berdasarkan Lama Fase Aktif.

Untuk mengetahui distribusi frekuensi tentang lama fase aktif dapat dilihat dari tabel berikut: 
Tabel 5.9 Distribusi Frekuensi responden berdasarkan Lama Fase Aktif di BPM Atik Suharijati di Surabaya pada bulan April-Mei tahun 2015.

\begin{tabular}{lllllll}
\hline Jumlah & 9 & 75 & 3 & 25 & 12 & 100 \\
\hline
\end{tabular}

Tabel 5.10 menunjukkan dari 2 responden yang tidak mengalami kecemasan seluruhnya $(100 \%)$

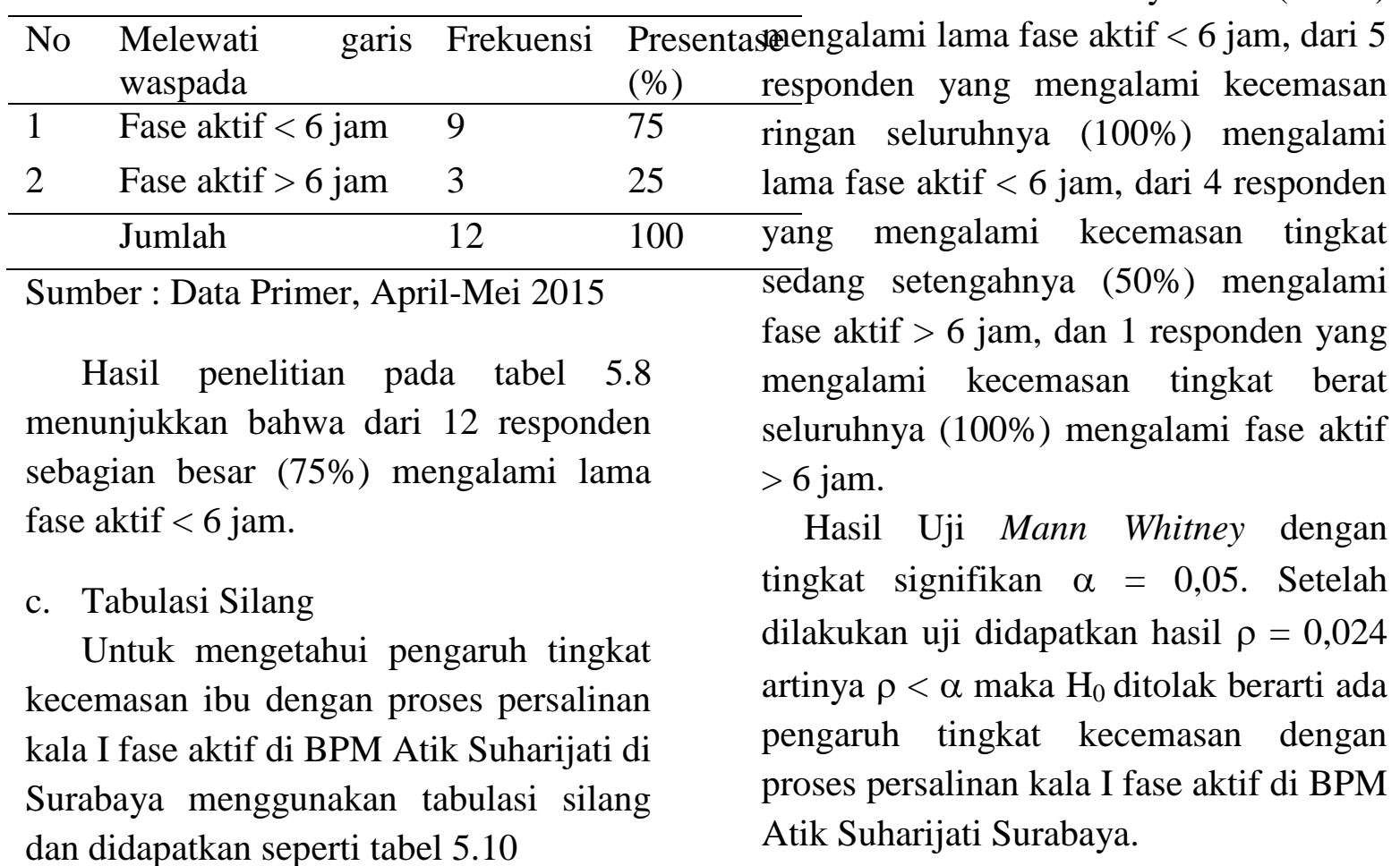

Tabel 5.10 Tabulasi silang tingkat kecemasan ibu dengan proses persalinan kala I fase aktif di BPM Atik Suharijati di Surabaya.

\begin{tabular}{|c|c|c|c|c|c|c|}
\hline \multirow{3}{*}{$\begin{array}{l}\text { Tingkat } \\
\text { kecemasan }\end{array}$} & \multicolumn{4}{|c|}{ Lama Fase Aktif } & \multirow{2}{*}{\multicolumn{2}{|c|}{ Total }} \\
\hline & \multicolumn{2}{|c|}{$\begin{array}{l}\text { Fase } \\
\text { aktif }< \\
6 \text { jam }\end{array}$} & \multicolumn{2}{|c|}{$\begin{array}{l}\text { Fase } \\
\text { Aktif > } \\
6 \text { jam }\end{array}$} & & \\
\hline & $\mathrm{N}$ & $\%$ & $\mathrm{~N}$ & $\%$ & $\mathrm{~N}$ & $\%$ \\
\hline $\begin{array}{l}\text { Tidak } \\
\text { cemas }\end{array}$ & 2 & 100 & 0 & 0 & 2 & 100 \\
\hline $\begin{array}{l}\text { Cemas } \\
\text { ringan }\end{array}$ & 5 & 100 & 0 & 0 & 5 & 100 \\
\hline $\begin{array}{l}\text { Cemas } \\
\text { sedang }\end{array}$ & 2 & 50 & 2 & 50 & 4 & 100 \\
\hline $\begin{array}{l}\text { Cemas } \\
\text { berat }\end{array}$ & 0 & 0 & 1 & 100 & 1 & 100 \\
\hline $\begin{array}{l}\text { Cemas } \\
\text { sangat } \\
\text { berat }\end{array}$ & 0 & 0 & 0 & 0 & 0 & 0 \\
\hline
\end{tabular}

\section{PEMBAHASAN}

Ibu yang baru mengalami proses persalinan atau dalam kebidanan biasa disebut nulipara adalah yang banyak mengalaminya. Kekhawatiran mereka muncul dengan beraneka ragam, seperti takut tidak bisa melahirkan secara normal, takut bayinya lahir cacat, takut tidak bisa selamat, dan lain sebagainya. Sivalitar (2007) menjelaskan bahwa kecemasan adalah perasaan yang dialami ketika seseorang terlalu mengkhawatirkan kemungkinan peristiwa yang menakutkan yang terjadi dimasa depan yang tidak bisa dikendalikan dan jika itu terjadi akan dinilai sebagai "mengerikan", sehingga jika keadaan ini tidak segera ditindak lanjuti maka akan 
berdampak pada proses persalinan tersebut. Trismiati (2006) menjelaskan bahwa kecemasan yang terjadi akan direspon secara spesifik dan berbeda oleh setiap individu. Faktor yang mempengaruhi dalam hal ini yaitu: usia, pendidikan, pengetahuan atau informasi, finansial, dukungan keluarga dalam hal ini adalah pendampingan saat persalinan, dan pengalaman.

Berdasarkan hasil penelitian tersebut banyak responden yang masih berusia dibawah 20 tahun, dimana secara fisik dan psikologis belum mencapai kematangan. Pada usia tersebut seseorang masih memiliki pola pikir yang belum cukup baik dimana pola pikir ini bisa mempengaruhi tindakan seseorang, tindakan yang dimaksud disini adalah penanganan suatu keadaan atau kondisi yang dianggap kurang baik olehnya, dalam hal ini adalah cemas. Responden banyak yang kurang bisa mengendalikan atau menangani kecemasannya dan hal ini tentunya akan berdampak pada proses persalinan yang mereka alami. Depkes RI (2009) memaparkan bahwa pada usia 1725 tahun tersebut seseorang memasuki usia remaja akhir dimana pemikiran mereka cukup logis, mulai bisa menerima masukan atau informasi dengan cukup baik, namun untuk pengalaman serta pemecahan masalah belum cukup matang bila dibandingkan dengan seseorang yang memasuki dewasa awal dan akhir. Nursalam (2001) semakin cukup usia, tingkat kematangan dan kekuatan seseorang akan lebih matang dalam berfikir dan bekerja. Stuart (2006) berpendapat bahwa seseorang yang mempunyai usia lebih muda ternyata lebih mudah mengalami gangguan kecemasan dari pada seseorang yang lebih tua, tetapi ada juga yang berpendapat sebaliknya.

Pendidikan yang ditempuh oleh responden sebagian besar adalah pendidikan menengah yakni sampai SMA atau SMK. Seseorang yang telah menempuh pendidikan menengah ini tentunya memiliki pengetahuan yang cukup baik bila dibandingkan dengan seseorang yang hanya menempuh pendidikan dasar. Pengetahuan tersebut dapat mempengaruhi seseorang dalam berfikir dan bertindak. Peningkatan pendidikan dapat pula mengurangi rasa tidak mampu untuk menghadapi stress atau kecemasan. Semakin tinggi pendidikan seseorang akan mudah dan semakin mampu menghadapi stress atau kecemasan yang ada. Inilah yang menyebabkan sebagian besar responden mengalami kecemasan ringan. Hal ini sesuai dengan teori (Nursalam, 2003) pendidikan berarti bimbingan yang diberikan oleh seseorang terhadap perkembangan orang lain menuju kearah suatu cita-cita tertentu. Tingkat pendidikan seseorang atau individu akan berpengaruh terhadap kemampuan berfikir, semakin tinggi tingkat pendidikan akan semakin mudah berfikir rasional dan menangkap informasi baru termasuk dalam menguraikan masalah yang baru.

Sebagian responden berpenghasilan antara satu sampai dua juta. Tidak di pungkiri tingkat kecemasan seseorang juga dipengaruhi oleh factor ekonomi. Sebagian kecil responden yang mengalami tingkat ekonomi yang rendah bingung untuk memikirkan segala sesuatu keperluan untuk dirinya dan 
bayinya kelak, mulai dari biaya persalinan, biaya kesejahteraan bayi dalam hal ini adalah baju, susu, dan lain sebagainya dan hal inilah yang menyebabkan tingkat kecemasan pada mereka meningkat. Responden yang sebagian besar mengalami perekonomian baik tentu akan sangat berbeda dengan responden yang mengalami perekonomian rendah. Mereka mengatakan tidak terlalu mengkhawatirkan soal biaya persalinan karena sudah mereka siapkan jauh-jauh hari, dan mereka juga tidak terlalu mengkhawatirkan biaya hidup untuk bayi mereka, sehingga hal inilah yang mempengaruhi seseorang mengalami tingkat kecemasan yang ringan. Aset berupa harta yang melimpah tidak akan menyebabkan individu tersebut mengalami stres berupa kekacauan finansial, bila hal ini terjadi dibandingkan orang lain yang aset finasialnya terbatas, karena dengan tingkat ekonomi yang bai tersebut dapat menentukan tersedianya fasilitas yang diperlukan untuk kegiatan tertentu seperti fasilitas untuk memudahkan mencari informasi, fasilitas tempat bersalin yang sesuai dengan kenyamanan masing-masing individu. Budiman dan Riyanto (2011) mengatakan bahwa status ekonomi baik lebih mudah tercukupi fasilitasnya dibanding keluarga dengan status ekonomi yang rendah Informasi akan meningkatkan pengetahuan seseorang dan pengetahuan akan meningkatkan kemampuan intelektual yang dapat meningkatkan kemampuan serta rasa percaya diri dalam menghadapi kecemasan yang akan mereka alami. Pengetahuan atau informasi merupakan fungsi penting untuk membantu mengurangi rasa cemas dan hal inilah yang menyebabkan mereka mengalami kecemasan ringan. Notoatmodjo (2003) telah menjelaskan bahwa pengetahuan adalah hasil dari tahu dan ini terjadi setelah orang melakukan pengindraan terhadap subyek tertentu. Semakin banyak pengetahuan yang dimiliki seseorang akan mengetahui mekanisme yang akan digunakan untuk mengatasi kecemasannya.

\section{SIMPULAN}

Berdasarkan hasil penelitian dan pembahasan mengenai pengaruh tingkat kecemasan ibu dengan proses persalinan pada kala I fase aktif maka dapat disimpulkan sebagai berikut :

1. Ibu bersalin di wilayah BPM Atik Suharijati Surabaya hampir setengahnya mengalami kecemasan ringan.

2. Ibu bersalin di wilayah BPM Atik Suharijati Surabaya sebagian besar mengalami lama fase aktif $<6$ jam.

3. Ada pengaruh tingkat kecemasan ibu dengan proses persalinan pada kala I fase aktif di BPM Atik Suharijati Surabaya.

\section{SARAN}

1. Diharapkan bagi bidan untuk memperhatikan kebutuhan psikologis pasien pada masa persalinan

2. Diharapkan keluarga dapat memberikan support kepada ibu yang dalam proses persalinan

\section{DAFTAR PUSTAKA}

Arikunto. S (2010). Prosedur Penilitian Suatu Pendekatan Praktek Rineka Cipta Jakarata 
Budiarti, E ( 2003), Metodologi Penlitian

Kedokteran: Jakarta : EGC

Buros, A.A. Lovich, R. Maxwell \& Shapiro, K (2002), Pemberdayaan Wanita Dalam Kesehatan Yayasan Essentrial Medica Yogyakarta.

Carpenito, S. (2007) Buku Saku Diagnosis Keperawatan, Jakarta : EGC

Chapman, V. (2006). Asuhan Kebidanan Persalinan dan pelahirn Jakarta : EGC

Dinas kesehatan Surabaya. (2008). Asuhan Persilanan Normal. Asuhan Esensial Persalian. Jakarta : JHPIEGO dan POGI

Herianato, B (2015). Metode Penilitian Kuantitatif Teori dan Aplikasi Surabaya : Putra Media Nusantar

Hidayat, A A. (2010). Metode Penilitian Kebidanan dan Teknik Analisia Data Jakarta : Salemba Medika

Herawati, ( 2009) Psikologi Ibu dan Anak, Jakarta : Salemba Medika

Kompas. (2007). Info Kesehatan, Dilihat tanggal 6 Maret 2015 Pukul 19.00 WIB

Koentjarningrat. (1985). Metode-Metode Penlitian Masyarakat, PT. Gramdia Jakarta

Manuaba, I, (1998). Ilmu Kebidanan, Penyakit kandungan, dan Keluarga Berencana untuk pendidikan Bidan, EGC. Jakarta
Maimunah, (2011). Kecemasan Ibu Hamil Menjelang Pesalinan Pertama Jurnal : Fakultas Psikologi. Universitas Muhammadiyh Malang.

Mochtar, (2004), Sinopsi Obsterri, Jakarta : EGC

Notoatmodjo, S (1997). Metodologi Penilitian Kesehatan, Rineka Cipta Jakarta

Notoatmodjo, S (2003). Pendidikan dan perilaku Kesehatan, Rineka Cipta. Jakarta

Notoatmodjo, S (2005). Ilmu Kesehatan Masyarakat,Rineka Cipta Jakarta

Nursalam \& Pariani (2003). Pendekatan Praktis Riset Keperawatan, Subeng Seto, Jakarta

Saifuddin, A (2002). Metodologi Penilitian, Pustaka Pelajar, Yogyakarta

Sifuddin, A (2003). Sikap Manusia Teori dan Pengukurannya Pustaka pelajar, Yogyakarta

Sarwono, S (1997). Sosiologi Kesehatan. Gadjamada University press, Yogyakarta Andi Offiset. Jakarta

Suria \& Sumantri (2002), Filsafat Ilmu Sebuah Pengantar Populer, Pustaka 